\title{
The only constant is change
}

\author{
Adam T. Woolley ${ }^{1}$
}

Published online: 18 September 2017

(C) Springer-Verlag GmbH Germany 2017

I am taking advantage of my first opportunity to address the readers of Analytical and Bioanalytical Chemistry (ABC) in an Editorial to talk about changes within the Editors' structure at $\mathrm{ABC}$, and also to emphasize many things about $\mathrm{ABC}$ that will remain unchanged. First, the change: earlier this year the $\mathrm{ABC}$ Editors decided to appoint a Chair Editor to serve as the leader of our editorial team. We also agreed on the Chair Editor's responsibilities, some of which are coordinating decision making, aiding in identification and implementation of strategic directions, being a spokesperson for $\mathrm{ABC}$, and serving as the initial scientific contact for the $\mathrm{ABC}$ community. In our annual $\mathrm{ABC}$ Editors Meeting in Heidelberg, Germany, this June, I was appointed as Chair Editor. I'm still learning all that the Chair Editor responsibilities entail, but I am excited to help move the journal forward in my new role.

I am well aware of ABC's strong European connections, and during my time as an editor for $\mathrm{ABC}$ I have developed a greater appreciation for and understanding of the high quality of scientific work of my European colleagues. As a scientist based in the United States, I look to Europe as much as or even more than I do to my own country now for global and scientific leadership. As Chair Editor, I will be attending European conferences, Euroanalysis, Analytica and so on, to get to know my European colleagues better and to see all the exciting work being done.

Now, even with this change in appointing a Chair Editor, many things at $\mathrm{ABC}$ will remain constant. All Editors will still be ambassadors for $\mathrm{ABC}$ in their respective scientific communities and geographical regions. $\mathrm{ABC}$ will continue publishing

Adam T. Woolley

woolley-abc-editor@byu.edu

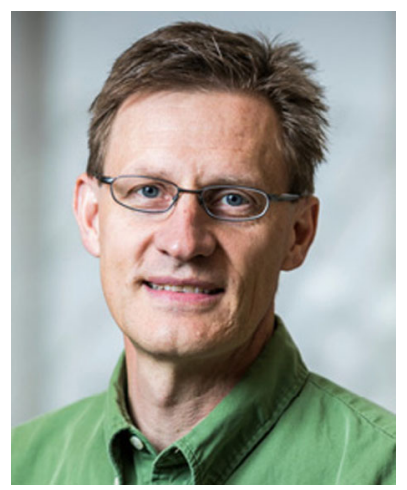

innovative and significant papers across the spectrum of analytical and bioanalytical chemistry. Distinctive features of our journal, including Topical Collections, Papers in Forefront, Highlights and Spotlights, will remain prominent. ABC will carry on and strengthen its synergistic relationship with European scientific owner-societies. ABC will continue to welcome high-quality submissions from across the globe. And, as always, we will rely heavily on your expertise as peer reviewers to ensure the excellence of what we publish.

I welcome your ideas, suggestions or recommendations about how we can strengthen $\mathrm{ABC}$ in the years to come. And I look forward to working together with Springer/ABC, the owner-societies, my fellow editors, authors, reviewers, and all readers of $\mathrm{ABC}$ to make our journal the best it can be.

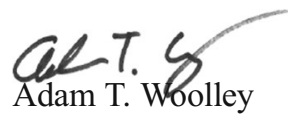

Chair Editor, ABC

woolley-abc-editor@byu.edu

Chemistry and Biochemistry Department, Brigham Young University, Provo, UT, USA 